\title{
Editorial
}

\section{Editorial: Bringing CORR's Global Readers the Best in Orthopaedic Research from China and Latin America}

\author{
Seth S. Leopold MD
}

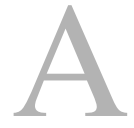

lmost 4 years ago in this space I made the case that Clinical Orthopaedics and Related Research ${ }^{\circledR}$ was "the world's general-interest orthopaedic journal" [2], and supported the claim using data demonstrating CORR's extraordinary international reach. We believe now, as we did then, that to address the global problems of musculoskeletal injury and disease, a leading journal needs to attract the best research from around the

The author certifies that neither he, nor any members of his immediate family, have any commercial associations (such as consultancies, stock ownership, equity interest, patent/licensing arrangements, etc) that might pose a conflict of interest in connection with the submitted article. All ICMJE Conflict of Interest Forms for authors and Clinical Orthopaedics and Related Research ${ }^{\mathbb{R}}$ editors and board members are on file with the publication and can be viewed on request.

The opinions expressed are those of the writers, and do not reflect the opinion or policy of $C O R R^{\circledR}$ or The Association of Bone and Joint Surgeons ${ }^{\circledR}$.

S. S. Leopold MD ( $ه)$

Clinical Orthopaedics and Related

Research $\AA$, 1600 Spruce St.,

Philadelphia, PA 19103, USA

e-mail: sleopold@clinorthop.org world, and then disseminate the findings to providers everywhere.

Because of that belief, we have intensified our international efforts in the last several years with good effect. In 2016 (the last year for which we have complete data), readers downloaded nearly 3 million $C O R R^{\circledR}$ articles in fulltext form. This volume has approximately doubled over the last 4 years, and $61 \%$ of those who downloaded our journal's articles last year resided outside the United States. In addition, $C O R R^{\mathbb{R}}$ more than doubled the number of subscribers to our monthly electronic tables of contents in 2015-2016, and other arrangements with domestic and international societies over that time have provided full-text access to more than 10,000 other new readers the world over. A bit closer to home, we are especially proud that the Association of Bone and Joint Surgeons ${ }^{\circledR}$ now provides the electronic table of contents and full-text access to CORR to every active member of the American Academy of Orthopaedic Surgeons.

With such wide distribution, perhaps it is no surprise that CORR's manuscript-submission volume-which hit another high in 2016-continues to grow, as does the proportion of manuscripts from around the world. In 2016, about $55 \%$ of the papers we received came from authors outside the United States, although at this time, most papers we publish still are from USbased author groups.

The difference between the proportions of manuscripts submitted (mostly international) and manuscripts published (mostly domestic) likely reflects differences in biomedical research infrastructure, which is comparably more developed in North America than it is in other parts of the world. But this too is changing. Governments in Asia (particularly China) have increased their investments more than threefold between 2004 and 2012, even as the rate of growth of funding in the United States has fallen off during that time [3]. China's investment in research continues to boom, and now has caught up with that of the European Union, as a function of gross domestic product (GDP) [4]. To the degree that articles published support the development of new ideas in the pipeline, CORR's usage tends to confirm that things are heating up in China. Surgeons in more than 100 countries downloaded CORR's content last year; 
China was third on that list, behind only the United States and the United Kingdom in terms of usage. I expect China's heavy investments in research infrastructure will result both in continued growth of manuscript submissions to orthopaedic journals and, more importantly, continued improvement in the quality of the work. This is likely to result in higher proportions of papers accepted for publication from that part of the globe.

But Latin America, the world's other major developing economy, is another matter where scientific production is concerned. Although the rate of population growth in Latin America is some three times greater than that observed in North America [5], Latin American research contributions fall far short of what one might predict on basis of population or even of GDP [6]. Although research and development spending in Argentina and Brazil is growing faster than are their respective economies, Brazil is the only country in the region spending more than $1 \%$ of GDP on research; by contrast, China and the European Union spend about $2 \%$, and the United States about $2.8 \%[4,6]$. To be sure, it is difficult to develop biomedical infrastructure in the face of political instability and sometimes-dire poverty, both of which are present to varying degrees across Latin America. One hopes and imagines that as these conditions ameliorate, scientific output from Latin America will increase both in quantity and quality.

At $C O R R^{\circledR}$, we seek not only to publish the best work from around the world and disseminate that work wherever surgeons practice, but also to support and recognize those making the discoveries. With that in mind, each year we evaluate all the papers we receive from the two fastest-developing parts of the world-China and Latin America-and give a "Best Paper" award to one from each.

The best paper from China in 2016 was "Reoperation After Cervical Disc Arthroplasty Versus Anterior Cervical Discectomy and Fusion: A Meta-analysis" by Zhong and colleagues [7]. This high-quality synthesis of 12 randomized trials containing more than 3200 patients found that cervical disc arthroplasty resulted in fewer reoperations than did anterior cervical discectomy and fusion; however, the authors correctly cautioned that most of these studies were industry funded, there was a suggestion of publication bias in their funnel plots (indicating perhaps that smaller, nodifference trials have been performed but have not been published), and that although they restricted inclusion to studies with at least 2 years of followup, these procedures need to serve patients for far longer, and so additional clinical surveillance will be very important. If you have not seen this paper, it is worth a careful look even if you do not perform spine surgery. It is an exceptionally thorough and well-presented metaanalysis, and can serve as an aspirational standard for other articles of that genre.

In this issue of $C O R R^{\circledR}$, we are proud to publish the award winner for the best paper from Latin America in 2016, a large and comprehensive comparison of endoprosthetic reconstruction and osteoarticular allograft after tumor resections of the proximal tibia [1]. With patients from two major tumor centers in Argentina and nearly 400 patients, I expect this paper by Albergo and colleagues to be as definitive a look at this topic as we are likely to see. Somewhat surprisingly (at least to me), osteoarticular allografts held up as well as the endoprostheses, and there were no differences in Musculoskeletal Tumor Society scores or late amputations between the groups. This might cause some surgeons who have moved away from osteoarticular allografts, particularly in this most-challenging anatomic location, to give the technique another look.

My congratulations go out to both award winners. I encourage clinician scientists and laboratory scientists from China and Latin America to continue to send their best work to $C O R R^{\circledR}$. We will give these awards again next year, and we will be sure that the winners - along with all the other content we publish in $C O R R^{\circledR}$, 


\section{Editorial}

the world's general-interest orthopaedic journal-are promoted and enjoyed by readers everywhere.

\section{References}

1. Albergo JI, Gaston CL, Aponte-Tinao LA, Ayerza MA, Muscolo L, Farfalli GL, Jeys LM, Carter SR, Tillman RM, Abudu AT, Grimer RJ. Proximal tibia reconstruction after bone tumor resection: Are survivorship and outcomes of endoprosthetic replacement and osteoarticular allograft similar? Clin Orthop Relat Res. [Published online ahead of print April 21,
2016]. DOI: 10.1007/s11999-0164843-y.

2. Leopold SS. Editorial: Clinical Orthopaedics and Related Research-The world's general-orthopaedic journal. Clin Orthop Related Res. 2013;471: 2417-2418.

3. Moses $\mathrm{H}^{\text {rd }}$, Matheson DH, CairnsSmith S, George BP, Palisch C, Dorsey ER. The anatomy of medical research: US and international comparisons. JAMA. 2015;313:174-89.

4. The Organisation for Economic Cooperation and Development (OECD). Gross domestic spending on R\&D. Available at https://data.oecd.org/ rd/gross-domestic-spending-on-r- d.htm\#indicator-chart. Accessed on December 19, 2016.

5. Statista: The Statistics Portal. Natural rate of population growth by continent in 2014. Available at https://www.statista.com/statistics/270859/natural-rate-of-population-growth-by-continent/. Accessed on December 19, 2016.

6. Van Noorden R. The impact gap: South America by the numbers. $\mathrm{Na}$ ture. 2014;510:202-203.

7. Zhong Z-M, Zhu S-Y, Zhuang J-S, Wu Q, Chen J-T. Reoperation after cervical disc arthroplasty versus anterior cervical discectomy and fusion: A meta-analysis. Clin Orthop Relat Res. 2016;474:1307-1316. 